\title{
$\cos 850$
}

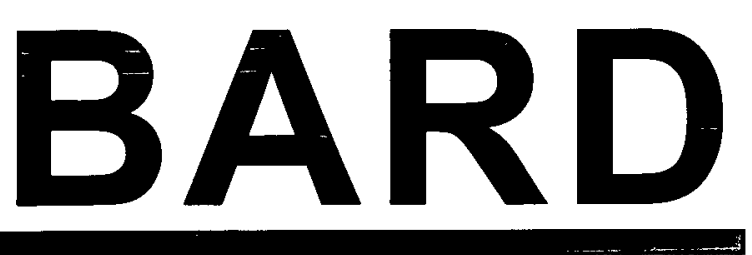

\section{FINAL REPORT}

\section{PROJECT NO. IS-3110-99}

Breed Improvement of Tilapia: Selective Breeding for Cold Tolerance and for Growth Rate in Fresh and Saline Water

G. Hulata, G.A.E. Gall

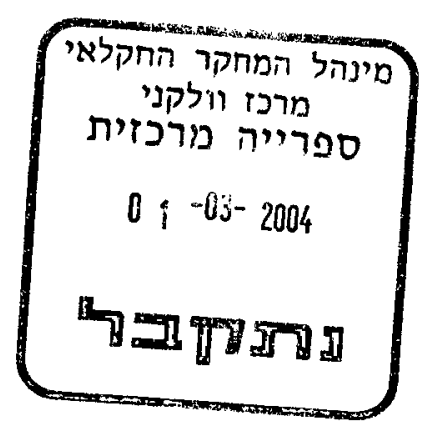


BARD Final Scientific Report

Cover Page

Date of Submission of the report: November $1^{\text {st }}, 2003$

BARD Project Number: IS-3110-99CR

Project Title: Breed improvement of tilapia: Selective breeding for cold tolerance and for growth rate in fresh and saline water

Investigators

Institutions

Principal Investigator $(\mathbf{P I})$,

Gideon Hulata

Agricultural Research Organization

Co-Principal Investigator (Co-PI):

Graham A.E. Gall

University of California Davis

Collaborating Investigators:

Keywords not appearing in the title and in order of importance. Avoid abbreviations.

Abbreviations commonly used in the report, in alphabetical order:

Budget: IS: $\$ 195,000$

US: $\$ 78,000$

Total: $\$ 273,000$

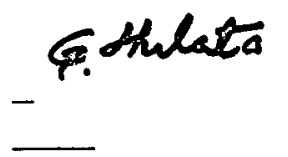

Signature

Principal Investigator

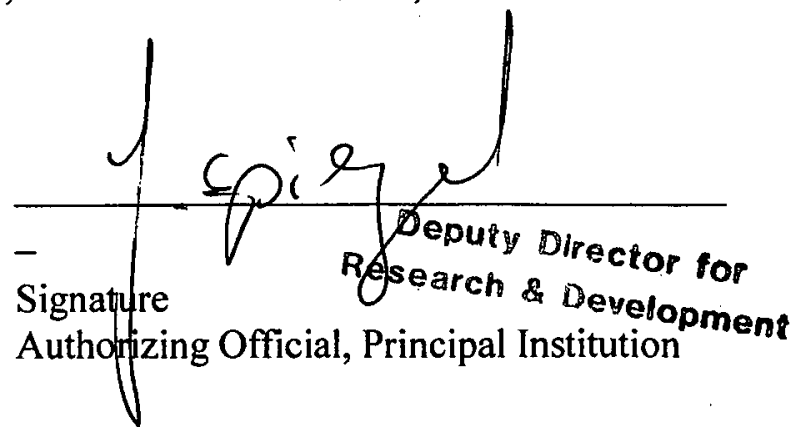


Abstract (one page maximum, single spaced), include:

The main objective of this project was to initiate a breeding program to produce cold-tolerant and salinity-tolerant synthetic breeds of tilapia, from a base population consisting of a four-species hybrid population created under an earlier BARD project. A secondary objective was to estimate genetic parameters for the traits growth rate under fresh- and salt-water and for cold tolerance. A third objective was to place quantitative trait loci that affect these traits of interest (e.g., growth rate in fresh-water, salt-water and cold tolerance) on the growing linkage map of primarily microsatellite loci.

We have encountered fertility problems that were apparently the result of the complex genetic structure of this base population. The failure in producing the first generation of the breeding program has forced us to stop the intended breeding program. Thus, upon approval of BARD office, this objective was dropped and during the last year we have focused on the secondary objective of the original project during the third year of the project, but failed to perform the intended analysis to estimate genetic parameters for the traits of interest.

We have succeeded, however, to strengthen the earlier identification of a QTL for cold tolerance by analyzing further segregating families. The results support the existence of a QTL for cold tolerance on linkage group 15, corresponding to UNH linkage group 23. The results also indicate a QTL for the same trait on linkage group 12, corresponding to UNH linkage group 4. 


\section{Achievements}

The objectives project were: (1) to perform a selective breeding program for cold tolerance and growth rate in freshwater and for growth rate in saltwater, using the $\mathrm{F}_{2}$ generation of a $4 \mathrm{WC}$ from the ACO base population produced under BARD project US-2664-95; (2) to estimate genetic parameters for the three traits from data obtained from performance testing a generational series from two species and from performance data obtained during the early generation of selection; and (3) to monitor the molecular marker genotypes found in the selected lines as a means of assessing the species of origin of the selected genome.

Unfortunately, none of these objectives could be achieved in full. We encountered fertility problems in the first year, which led us to delay production of Generation-1 of the breeding program to the second year. The 16 breeding families were over-wintered, and re-established in the spring of 2002. To our disappointment, the fertility problems encountered in 2001, and attributed then to the young age of the females, persisted in the second year. Most of our breeding families were spawning, but none of these spawns was fertile. We sacrificed a few males and found that they had under-developed testes. Some of them had only a low number of motile sperm. We had to conclude that the complex genetic structure of this base-population (second generation of the four species cross of Oreochromis aureus, $O$. niloticus, O. mossambicus and Sarotherodon galilaeus) has caused the fertility problem. Thus, we had reached a point where it was clear that we were unable to carry out our primary objective for this project.

The intended cooperation between the two PIs was not feasible, since the analytical role of the US partner could not have been realized.

The breeding of the six-generation series $\left(\mathrm{Oa}, \mathrm{Om}, \mathrm{F}_{1}, \mathrm{~F}_{2}, \mathrm{BCOa}, \mathrm{BCOm}\right)$ also met with problems. In the first two years we were not able to obtain all of them. In the last year we obtained all crosses within a reasonable time interval, although the numbers of families obtained from each

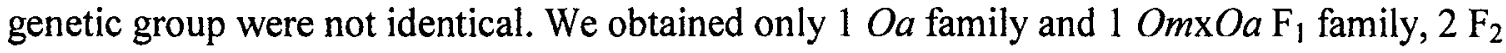
families, 3 families of each of the backcrosses, and many $O m$ families. The survival of the $O a$ family was low and only 40 remained when they reached tagging. These fish were used for two growth experiments - one in salt water (using fish nursed to an average weight of $\sim 20 \mathrm{~g}$ ) and the other in fresh water (using fish of an average weight of 4-50g). Technical difficulties prevented performing the two simultaneously, as originally planed. Due to the lack of one parental group (Oa) which was stocked at a very low density and was not accountable at the termination of the salt 
water growth test, and the unequal number of replicated families per group, the intended analysis to estimate genetic parameters could not be performed.

The differences in growth rate among the remaining five groups were significant at the termination of the test $(\mathrm{P}=0.056)$; there was, high intra-group variation (s.d. ranged from 14 to $18 \mathrm{~g}$ among groups and from 11 to $13 \mathrm{~g}$ among replicate tanks). However, as can be seen from Figure 1, $O m$ and the $\mathrm{F}_{1}$ hybrid $O m \times O a$ seem to have grown better than the other groups.

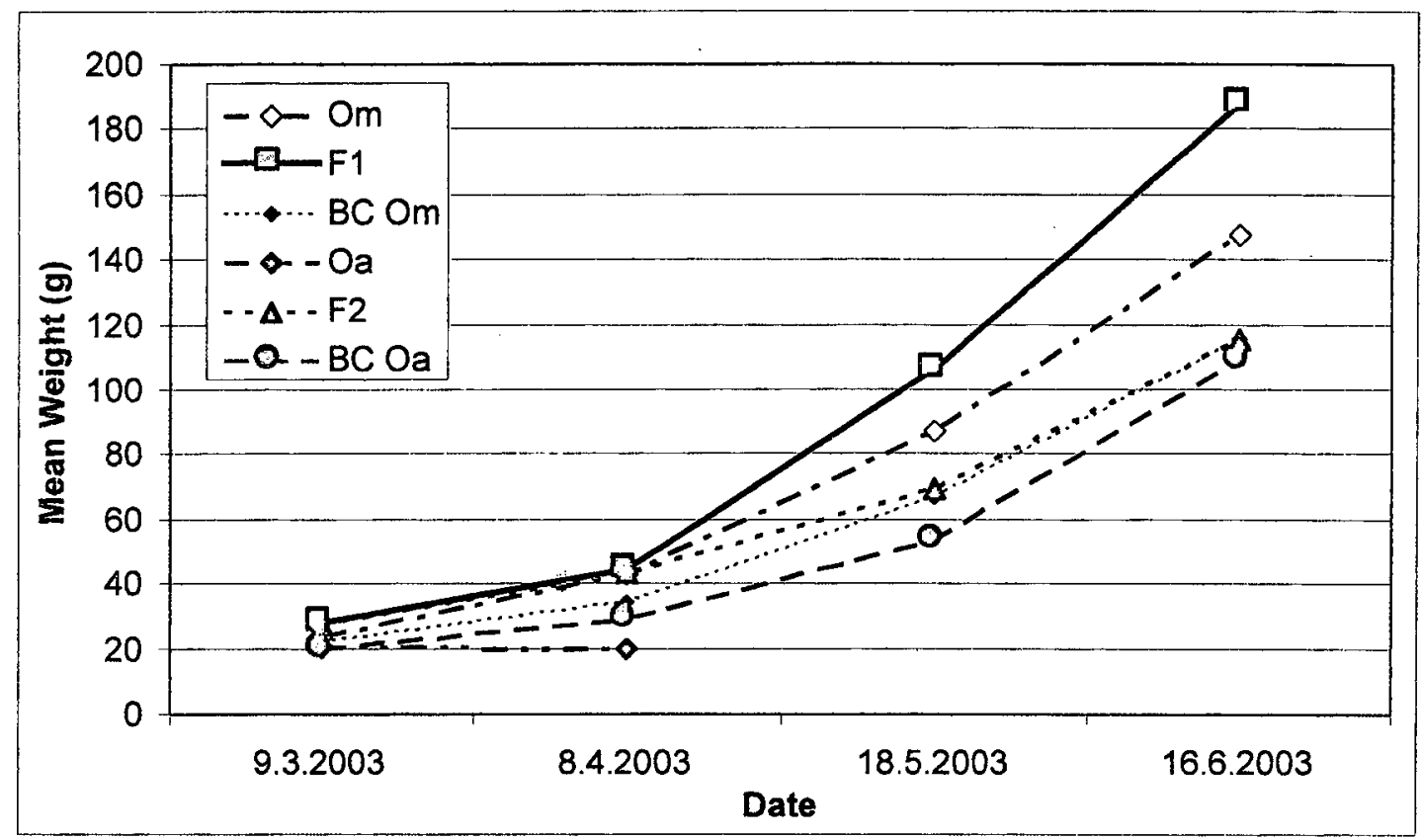

Figure 1. Growth curves of tilapia groups in salt water.

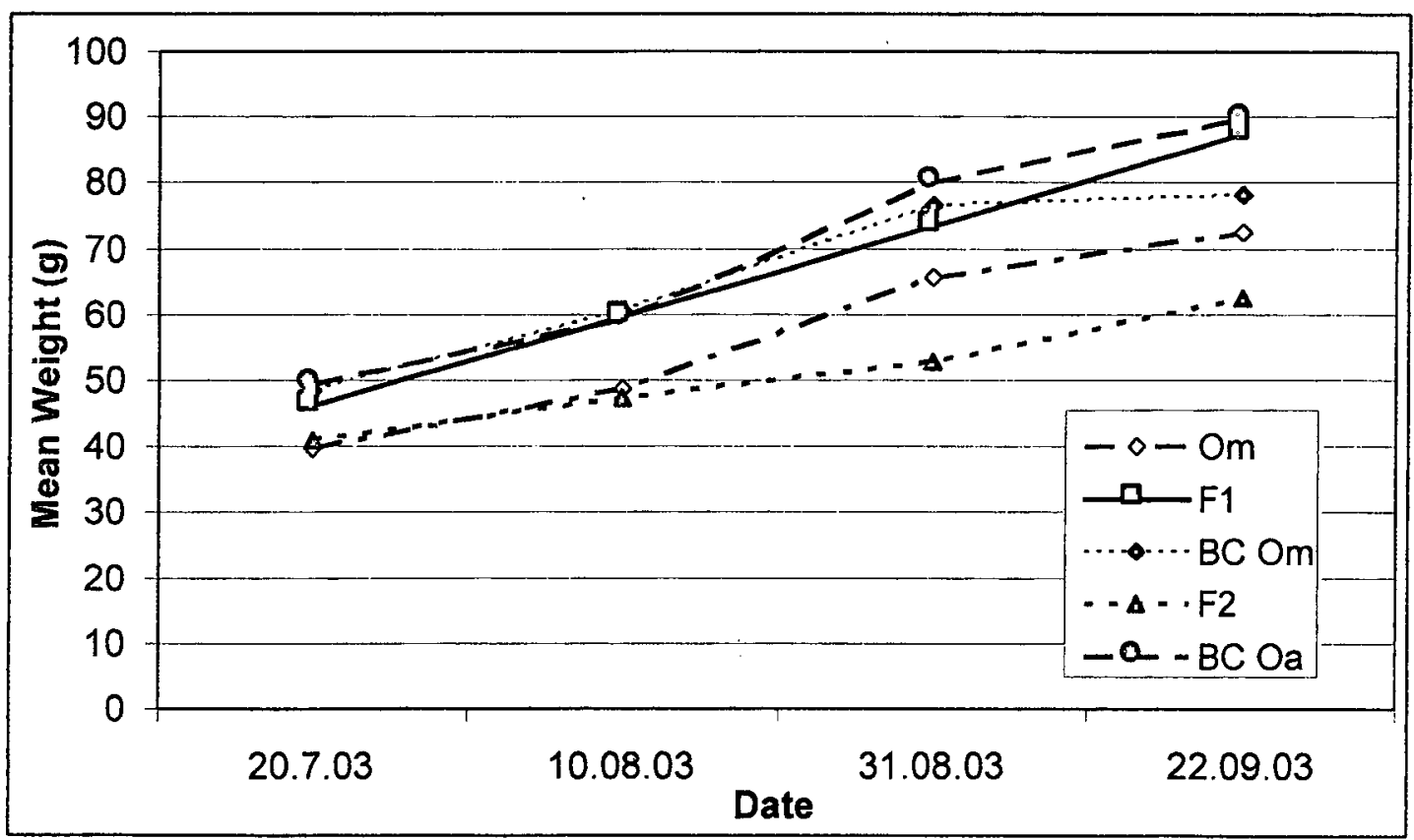

Figure 2. Growth curves of tilapia groups in fresh water. 
The differences in growth rate among the five groups tested in the fresh water experiment (Figure 2) were significant $(\mathrm{P}<0.01)$ when initial weight was used as a covariate in the model. The Oreochromis mossambicus and the $F_{2}$ grew significantly slower than the $F_{1}$ and the two backcross generations.

Comparison of the two experiments, even though not performed under the same conditions, reveals remarkable changes in ranking of the genetic groups. Om which was second to the $\mathrm{F}_{1}$ in the salt water experiment performs rather poorly in the fresh water experiment, as expected from what we know about their biology.

Since the breeding program was not on going, monitoring the molecular marker genotypes found in the selected lines was not possible. Instead, the UCD lab continued our efforts to place quantitative trait loci that affect the traits of interest (e.g., growth rate in fresh-water, salt-water and cold tolerance) on the tilapia linkage map. Thus, the only achievement of this project was the strengthening, by analyzing further segregating families, the earlier identification of a QTL for cold tolerance.

A genome scan, looking for QTL for the traits cold tolerance and weight in tilapia, was performed on a cross between a (Oreochromis mossambicus x O. aureus) male and a (O. niloticus $\mathrm{x}$ Sarotherodon galilaeus) female. Fifty four microsatellites and 23 AFLP primer combinations were genotyped, and testing for QTL was performed separately on segregation data from the two parents. The segregation of male alleles was associated with cold tolerance and weight at 10 and 7 marker loci, respectively. Likewise, segregation of female alleles was associated with cold tolerance and weight at 5 and 3 marker loci, respectively. To test the reproducibility of the results, putative QTLs from the genome scan were tested in another $(O m \times O a) \times(O n \times S g)$ family. One marker-trait association was found to be significant at $\alpha=0.05$ in both experiments, this being the association of female alleles at microsatellite $U N H 124$ to cold tolerance. Another association, that of male alleles at microsatellite $U N H 130$ to cold tolerance, was highly significant in the second experiment, although it was not so in the first. However, the same association has been reported in another study. More microsatellites were genotyped on the linkage group containing markers UNH124 and $U N H 130$, linkage groups 12 and 15, respectively, and interval mapping was performed. The results support the existence of a QTL for cold tolerance on linkage group 15, corresponding to UNH linkage group 23. The results also indicate a QTL for the same trait on linkage group 12 , corresponding to UNH linkage group 4. 


\section{List of Publications}

Gideon Hulata (2003). Fertility problems in a second generation of a four-species tilapia cross (technical note). (in preparation).

Thomas Moen, Jeremy J. Agresti, Avner Cnaani, Hillary Moses, Thomas R. Famula, Gideon Hulata, Graham A. E. Gall, Bernie May (2003). A genome scan of a four-way cross tilapia family supports the existence of a QTL for cold tolerance on UNH chromosome 23. (Aquaculture Research, Submitted). 
Publication Summary (numbers)

\begin{tabular}{|l|c|c|c|c|}
\hline & $\begin{array}{c}\text { Joint } \\
\text { IS/US } \\
\text { authorshi } \\
\mathrm{p}\end{array}$ & $\begin{array}{c}\text { US } \\
\text { Authors } \\
\text { only }\end{array}$ & $\begin{array}{c}\text { Israeli } \\
\text { Authors } \\
\text { only }\end{array}$ & Total \\
\hline Refereed (published, in press, accepted) & & & & \\
\hline Submitted, in review, in preparation & 1 & & 1 & 2 \\
\hline Invited review papers & & & & \\
\hline Book chapters & & & & \\
\hline Books & & & & \\
\hline Master theses & & & & \\
\hline Ph.D. theses & & & & \\
\hline Abstracts & & & & \\
\hline Not refereed (proceedings, reports, etc.) & & & & \\
\hline
\end{tabular}

Postdoctoral Training: List the names and social security/identity numbers of all postdocs who received more than $50 \%$ of their funding by the grant.

Cooperation Summary (numbers)

\begin{tabular}{|l|c|c|c|c|}
\hline & $\begin{array}{c}\text { From US } \\
\text { to Israel }\end{array}$ & $\begin{array}{c}\text { From Israel } \\
\text { to US }\end{array}$ & $\begin{array}{c}\text { Together, } \\
\text { elsewhere }\end{array}$ & Total \\
\hline $\begin{array}{l}\text { Short Visits \& } \\
\text { Meetings }\end{array}$ & 1 & & & 1 \\
\hline $\begin{array}{l}\text { Longer Visits } \\
\text { (Sabbaticals) }\end{array}$ & & & & \\
\hline
\end{tabular}

\section{Description of Cooperation:}

Dr. Gall spent 10 days in Israel (August 18-28 2000), during which the whole breeding program was re-discussed to make sure we are not facing any pitfalls not envisioned during preparation of the proposal.

Patent Summary (numbers)

\begin{tabular}{|l|c|c|c|c|}
\hline & $\begin{array}{c}\text { Israeli inventor } \\
\text { (s) only }\end{array}$ & $\begin{array}{c}\text { US inventor (s) } \\
\text { only }\end{array}$ & $\begin{array}{c}\text { Joint } \\
\text { IS/US inventors }\end{array}$ & Total \\
\hline Submitted & & & & \\
\hline $\begin{array}{l}\text { Issued } \\
\text { (allowed) }\end{array}$ & & & & \\
\hline Licensed & & & & \\
\hline
\end{tabular}

